\title{
Technical documents to aid decision making for the off-site responses to major nuclear accidents during the intermediate and late phases
}

\author{
J.-M. Métivier
}

\author{
Laboratory of Environmental Modelling, Department of Laboratory Research, \\ Division of Environmental Protection, Institute of Nuclear Protection and Safety, \\ CE Cadarache, 13108 Saint-Paul-lez-Durance cedex, France
}

\begin{abstract}
When managing the intermediate and late phases following the release of radioactivity to the environment after a major nuclear accident, decision makers need material to support the advice they give to the authorities, and communications issued to the media. In order to document and justify their decisions, they can potentially use a wide range of tools and types of information. However, the experience gained during emergency exercises shows that only a few documents are operationally used, and such documents are often the same: cartography of deposits, spatial evolutions of doses, spatial evolutions of concentration in milk, leafy vegetable and beef meat, associated evolutions through time, population concerned and location of dwelling places, quantity of major agricultural products concerned, land use in contaminated areas.

Deposits should be broken down per radioactive nuclide. For doses, a link with the consequences of the emergency phase should be kept through the account of the radiological impact due to the exposure to the radioactive plume. Generally, the most illustrative documents are maps and time dependent graphics, as a way to get at the same time a synoptic view of the direct consequences of the accident, the influence of some crucial phenomena (radioactive decay), and the potential consequences of mitigation actions on the field, added to the attempt at interpreting their interplay for the best management of the situation. From some examples taken during crisis exercises, we shall see what such documents with which decision-makers can made their decisions, and justify their rationale, are.
\end{abstract}

\section{Foreword: The Institute of Protection and Nuclear Safety's mission (IPSN)}

The mission of the IPSN is to help control nuclear hazards and their consequences on the environment and concurrently to conduct research and appraisals in all fields linked to the assessment of these risks. On these grounds, one of the IPSN's field of activity is to conduct appraisals and advise the Authorities on technical, health and environmental problems in the event of a nuclear crisis.

To that end, the IPSN must play a key role with regards to actions pertaining to the post-accidental phase consecutively to an accident involving radioactive material outside a facility.

Furthermore, in the event of a serious accident in a foreign nuclear facility, the IPSN must also give its technical opinion on the situation and study its possible consequences, notably for the French territory.

Finally, the IPSN must give some advice and assistance in all accidental situations liable to lead radioactivity exposition.

\section{PROBLEM}

During the post-accidental phase of the nuclear crisis of a PWR (pressurised water reactor), the decisionmakers must reply to different questions from the public authorities or media. In order to manage and guide their choices, tools and information are put at the disposal of the experts.

For the post-accidental phase, two terms must be taken into account: the short term (from one day to few weeks) and the intermediate to long term (from some weeks to some years).

The short-term management must be fast and "be similar to the accidental phase management"; in particular when simultaneously or almost simultaneously carried out at the accidental phase. It leads to decisions made such as banning of milk and leafy vegetable consumption as soon as deposits are in the soil, removal of livestock from the pasture when necessary, then to the banning of consumption of other products (meat, eggs, etc.).

The second term management (which will not be dealt with here) deals more with the suggestion of countermeasures endeavouring to reduce the impact in the different components of the environment and man. It should give which countermeasures are required in order to avoid destruction of certain products (transformation of milk into butter and/or cheese, tinned fresh products, etc.). Finally, it should give advice on rehabilitation methods for contaminated zones.

The decision-makers should most often react on the ground and sometimes in a delocalised manner, it is therefore more important for them to know the environment that is influenced by the problem and this at the time of the accident:

- the natural surrounding,

- the human and economical surrounding (demography, agriculture, industry, etc.) and

- the local specificities (life forms, leisure activities, etc.). 


\section{DOCUMENTS NECESSARY FOR DECISION MAKING}

In order to diagnose the situation (deposit zone) and to issue different forecasts for different management strategies on the territory under consideration (prohibition of consumption), experts, software and data are available to the decision-makers in order to deal with the considerable flow of information (calculated data and measured data) and to transform this into decision documents.

Only some documents and always the same documents will be used to make the decision. These are in particular:

- the spatial distribution of deposits,

- the spatial developments of the concentration index of some products,

- the spatial developments of total doses,

- the places of habitat and the number of inhabitants, the agricultural productions and the land occupancy under consideration.

Documents issued to the decision-maker are in general maps enabling to have a flowchart view of the phenomena, the dependencies and spatial connections may thus take their place without losing their relative location.

\subsection{Deposits}

For the deposits, the spatial distribution of two radioactive nuclides is generally required (Table ], figure 1). It is reminded that the deposit day is the date upon which we may consider depositing to have finished.

Table 1 : Deposits

\begin{tabular}{|l|l|}
\hline $\begin{array}{c}\text { Radioactive } \\
\text { nuclide }\end{array}$ & \multicolumn{1}{c|}{ Term } \\
\hline $131 \mathrm{I}$ & $\begin{array}{l}\text { The day of deposit } \\
7 \text { days after the deposit }\end{array}$ \\
\hline $137 \mathrm{Cs}$ & The day of deposit \\
\hline
\end{tabular}
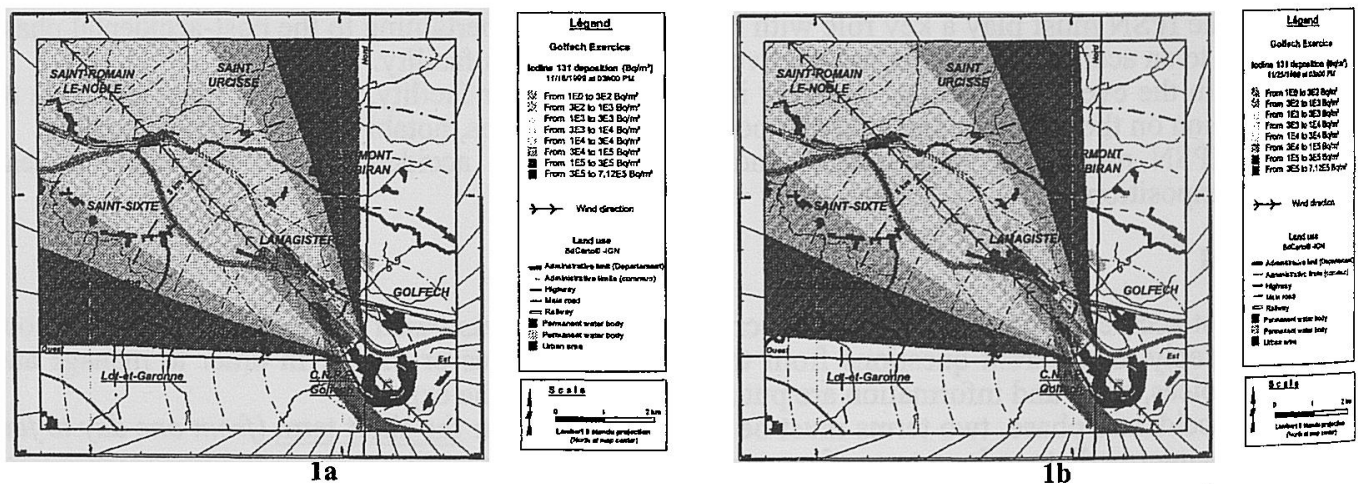

Figure 1 : Spatial representations of Iodine 131 deposits (Golfech exercise - March 21, 2001) The day of deposits (la) and seven days afterwards (1b)

\subsection{Concentration indexes}

Further to the concentration value reached by a product, it is the relative value of this with respect to a marketing limit, which speak for the decision-makers: if the index is greater than the unit, the concentration in the product is above the limit.

The development with time of the concentration for milk and leafy vegetables for 3 groups of radioactive nuclides is required, generally in the form of a graph, for maximum deposit values. It is easy to identify the number of days for which the product is contaminated above its marketing limit (figure 2). 


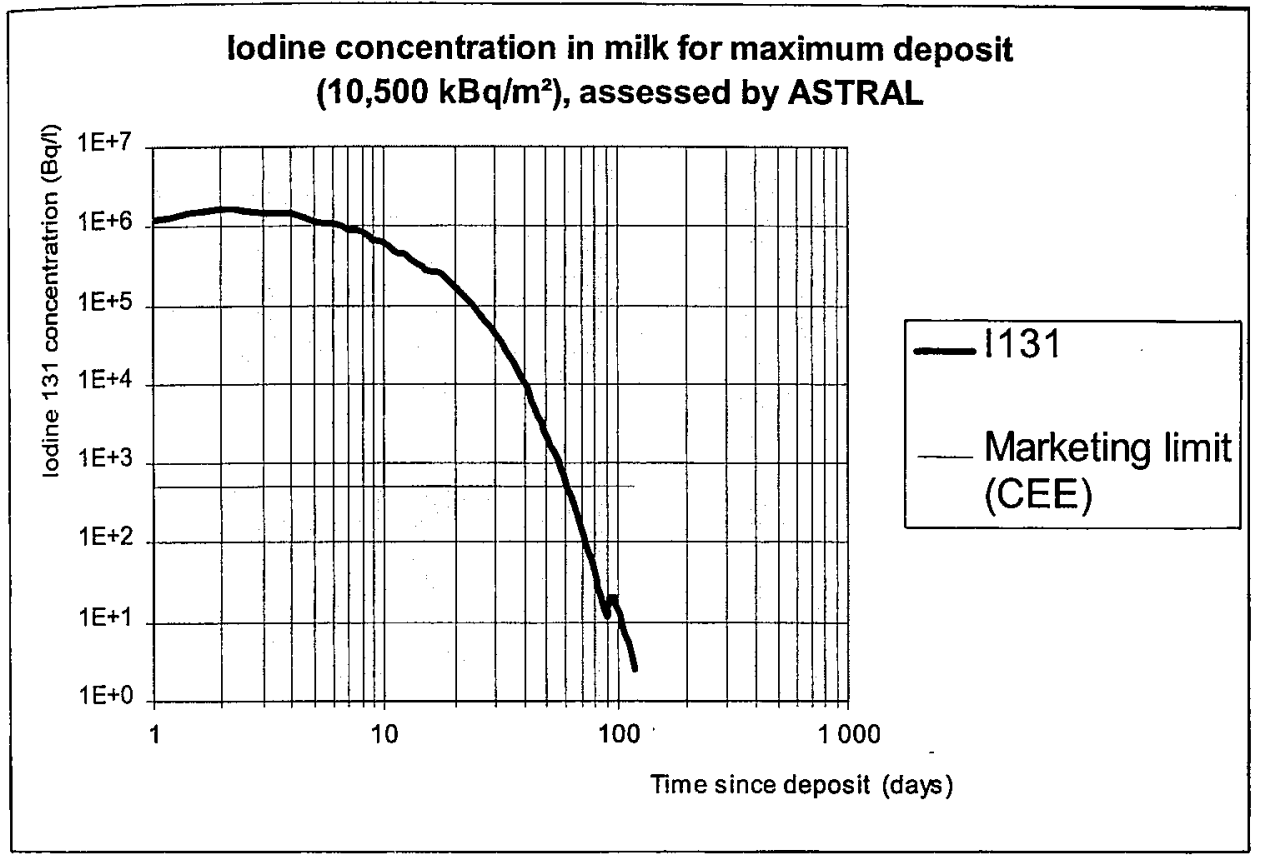

Figure 2: Time development for Iodine 131 concentration in milk to the point of maximum deposit $(2,080 \mathrm{~m}-\mathrm{N} 314)$

(BfS/IPSN exercise - June 2000)

Here we have an idea of real impact (in a binary manner: under and over) but we have no idea of the importance of the impacted area. The answer may only be found with the geographic representation for one given day, the document thus becomes really an aid document for decision making: should or shouldn't we react! on whichever zone (districts)". The binary representation is obviously too stringent. Two possible representations according to three or five colour codes are preferred (Tables 2 and 3). The spatial representations of three products are generally required as well as the maximum marketing limits reached in terms of surface, distance and time for milk (figures 2 and 3) and leafy vegetables for the different groups of radioactive nuclides.

Table 2 : Concentration indexes

\begin{tabular}{|l|l|l|}
\hline Product & Group & \multicolumn{1}{|c|}{ Term (after deposit) } \\
\hline Milk & lodine & $\begin{array}{l}\text { 1 day } \\
7 \text { days } \\
\text { 1 month } \\
\text { the day of highest iodine concentration }\end{array}$ \\
\hline Miik & Caesium & $\begin{array}{l}\text { I day } \\
1 \text { month } \\
1 \text { year } \\
\text { the day of highest iodine concentration }\end{array}$ \\
\hline $\begin{array}{l}\text { Teafy } \\
\text { Yegetables }\end{array}$ & Iodine & $\begin{array}{l}\text { Day of deposit } \\
7 \text { days } \\
\text { 1 month }\end{array}$ \\
\hline $\begin{array}{l}\text { Leafy } \\
\text { vegetables }\end{array}$ & Caesium & $\begin{array}{l}\text { Day of deposit } \\
\text { I month } \\
\text { I year }\end{array}$ \\
\hline
\end{tabular}

Table 3 : Colour codes for concentration indexes

\begin{tabular}{|l|l|}
\hline \multicolumn{1}{|c|}{ Colour } & \multicolumn{1}{|c|}{ Value } \\
\hline Green & Up to $30 \%$ of the marketing limit \\
Orange & From 30 to $300 \%$ \\
Red & Above 300\% \\
\hline Green & Up to $10 \%$ of the marketing limit \\
Light green & From $10 \%$ to $50 \%$ \\
Yellow & From 50 to $200 \%$ \\
Orange & From $200 \%$ to $1000 \%$ \\
Red & Above $1000 \%$ \\
\hline
\end{tabular}

Documents that are rarely required are given in italics 


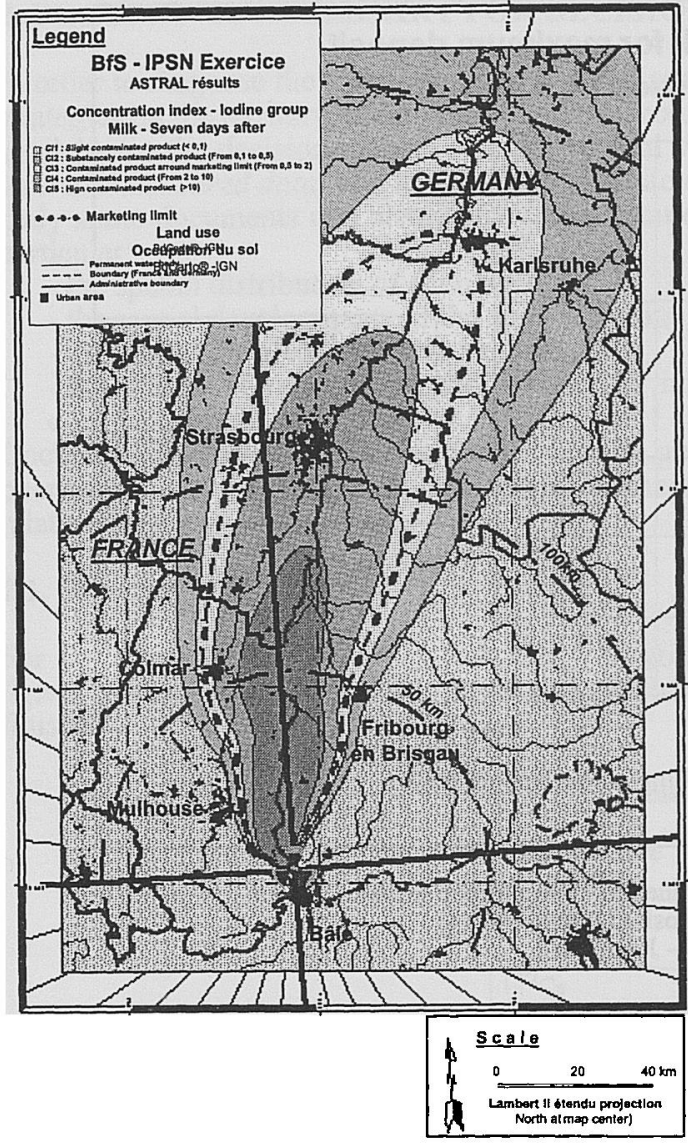

Figure 3 : Spatial representation of the concentration index in milk -Iodine Group - Seven days afterwards

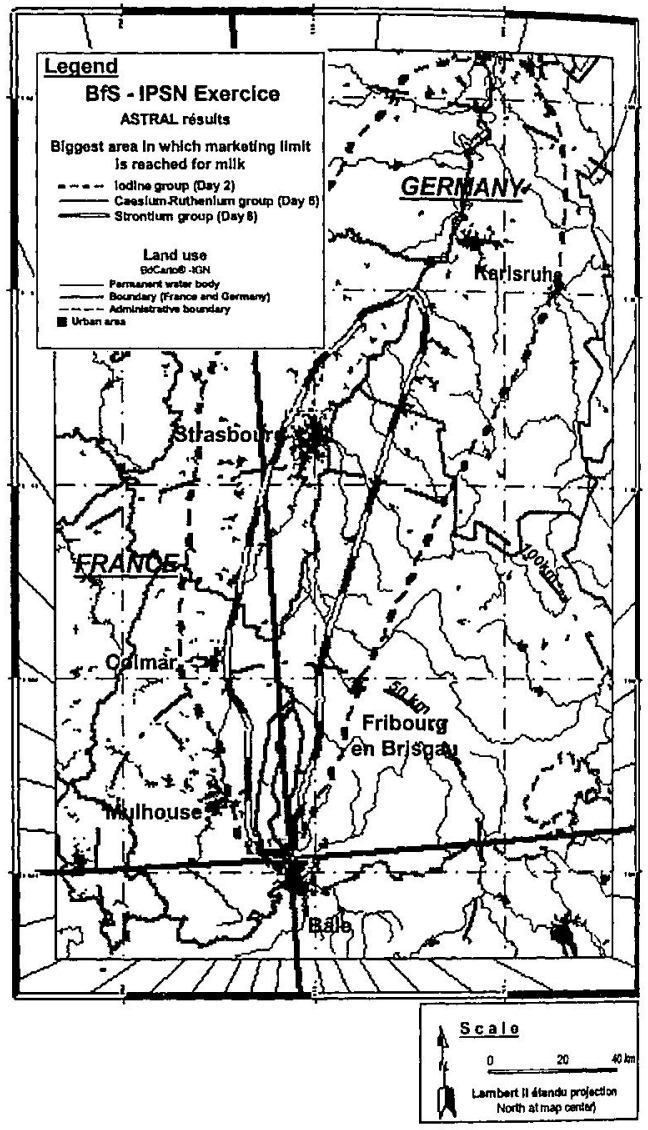

Figure 4 : Spatial representation of maximum marketing limits

(BfS/IPSN exercise - June 2000)

\subsection{Doses}

For several ages and life forms and for three dates, the spatial representation of efficient doses is required (deposits + ingestion + inhalation through deposits in suspension) for all radioactive nuclides together (Table 4 and figure $5 a$ ).

Table 4 : Doses

\begin{tabular}{|l|c|}
\hline Age and life form & Term (after deposit) \\
\hline Baby & 7 days \\
Very young child & I month \\
Very young rural child & 1 year \\
Young rural child & \\
Rural child & \\
Rural adolescent & \\
Rural adult & \\
\hline
\end{tabular}

Documents that are rarely required are given in italics 


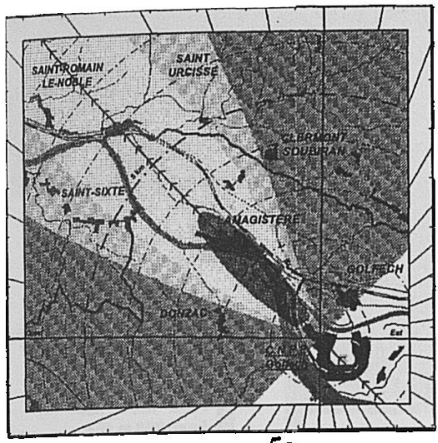

5a

5a- Total effective post-accidental doses

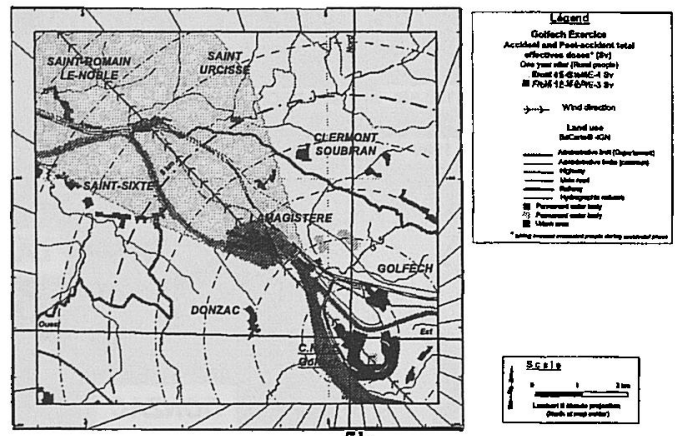

$5 \mathbf{b}$

(Golfech exercise - March 21, 2001)

5b- The sum of total accidental and post-accidental effective doses (taking into account doses avoided by evacuated populations)

For doses it is sometimes necessary to ventilate the fraction due to deposits, inhalation and ingestion and for this latter, the contribution of different products of food rations as well as that of each radioactive nuclide. In order to appreciate the importance it is necessary, besides, to add to this that of the accidental phase, taking into account (sometimes) the dose avoided by evacuated populations (figure $5 b$ ).

\subsection{Spatial analyses}

The occupation of zones said to be "affected" remains to be identified:

- where are the habitation places, which populations according to which age?

- which quantities of plant products, how many animals?

- surfaces and types of land occupation under consideration.

The extraction of this data enables, from the first day onwards, livestock to be taken in from the pasture, to be evacuated or to be culled to be known. This data combined with the calculated or measured concentrations enable the best strategy to draft countermeasures or to rehabilitate contaminated zones. Access to this information is only possible by means of acquisition of databases which are continuously updated (national or on the ground research, teledetection processing, etc.).

\section{CONCLUSION}

The experience acquired during different crisis exercises with a post-accidental phase and with regards to a PWR (pressurised water reactor), shows that questions which are systematically asked concern two radioactive nuclides, iodine 131 and caesium 137. Documents issued to the decision-maker are, in general, geographic representations, twenty or so may be requested but generally five or six are sufficient:

- spatial representation of iodine deposits the day of deposit,

- time development graph of concentration for milk for the maximum iodine deposit value,

- spatial representation of maximum marketing limits reached at the surface, at a distance and in time, for milk for the different groups of radioactive nuclides,

- populations, agricultural productions and land occupation under consideration.

The decision-making help systems should take into account this repeated request for documents by issuing, by default, all documents required to guide strategy, however, these systems should not be closed to these documents only, each site should in fact have its own local specificities. 


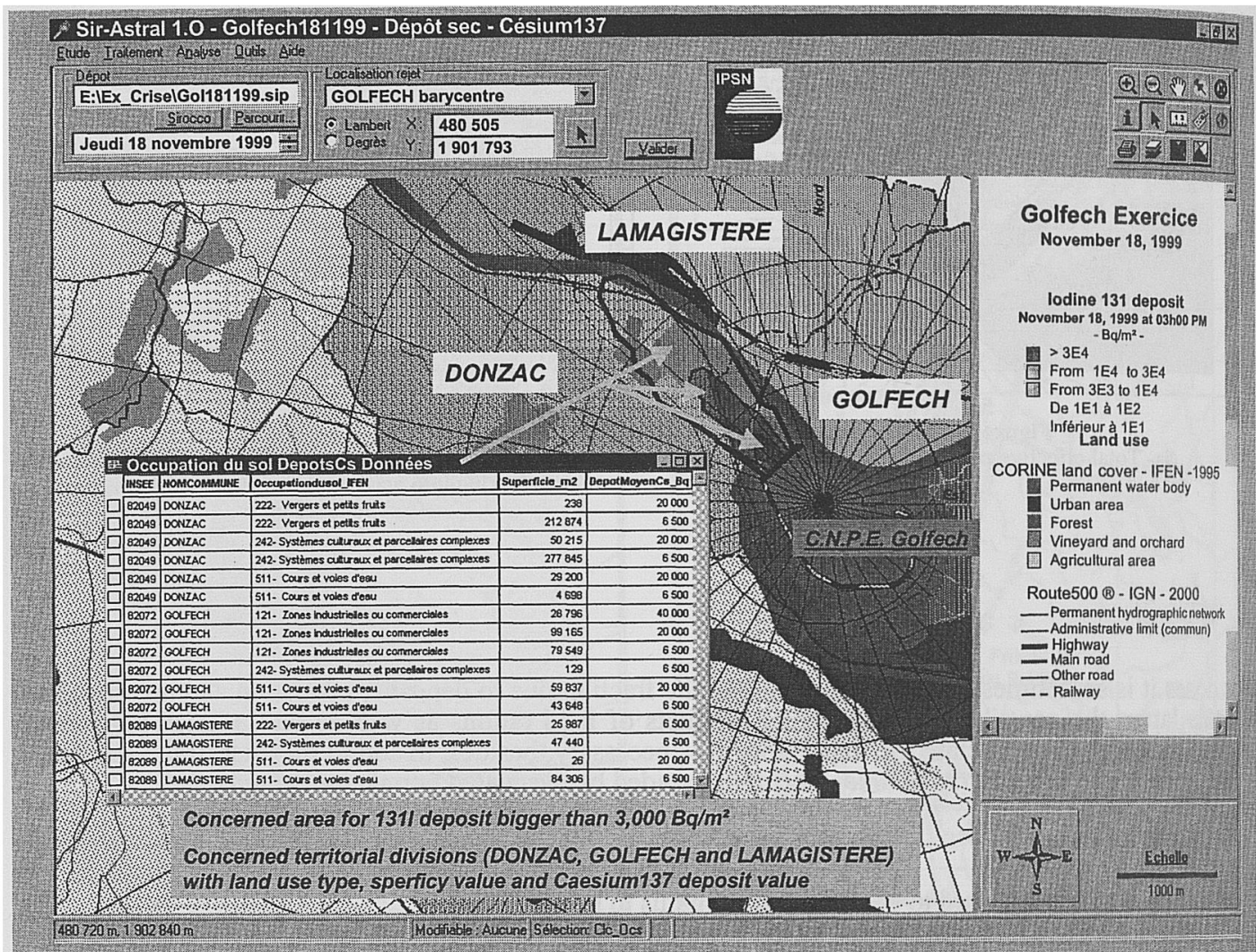

Figure 4: Spatial analysis - Identification of land occupation under consideration for a caesium 137 deposit (BASIIPSN exercise - June 2000)

\section{Bibliography}

[1]-J.M. Métivier, " "SIR-ASTRAL": a combined use of an atmospheric dispersion and a food-chain codes, completed by the functionalities of a GIS". Ecorad 2001, 3-7 September 2001, Aix-en-Provence, France

[2]-Maubert H., Renaud Ph., Bernié J.C., De Drouas G., Fache P., Métivier J.M., "ASTRAL: un logiciel pour l'évaluation des conséquences d'un rejet accidentel de radioactive nuclide dans l'environnement" Radioprotection Vol.32, n³, p.357 à 368, 1997.

[3]-Métivier J.M.,"Utilisation d'un Système d'Information Géographique lors de l'exercice de crise Becquerel". Rapport IPSN/DPRE/97-010P, 1997.

[4]-Mourlon C., "Description des fonctions et des paramètres du module de calcul ASTRAL version 1.1". Rapport IPSN/DPRE/SERE/98/033P, 1998.

[5]-Boyer P., "Interfaçage SIROCCO_CD-ASTRAL Étude de faisabilité et principes de base". Rappoit IPSN/DPRE/99-002P, 1998.

[6]-Métivier J.M., Boyer P. "Atmospheric dispersion code and radioecological and dosimetric impact code interfacing - Use of geographical information system software functions" ENVIROSOFT 2000 Eighth International Conference on Development International Conference and Application of computer Techniques to Environmental Studies, 28-30 June 2000 at University of the Basque Country, Bilbao, Spain 